\title{
ANALISIS KEBERLANJUTAN USAHATANI PADI SAWAH DI KECAMATAN SOREANG KABUPATEN BANDUNG
}

\section{Sustainable of Rice Farming in Soreang District of Bandung Regency}

\author{
Gilang Fauzi Dzikrillah ${ }^{\mathrm{a}}$, Syaiful Anwar ${ }^{\mathrm{b}}$, Surjono Hadi Sutjahjo ${ }^{\mathrm{c}}$ \\ ${ }^{a}$ Sekolah Pascasarjana, Institut Pertanian Bogor, Kampus IPB Darmaga, Bogor 16680 - \\ gilangfauzi78@yahoo.co.id \\ ${ }^{b}$ Departemen Ilmu Tanah dan Sumberdaya Lahan, Fakultas Pertanian, Institut Pertanian Bogor, Kampus IPB \\ Darmaga, Bogor 16680 \\ ${ }^{c}$ Departemen Agronomi dan Holtikultura, Fakultas Pertanian, Institut Pertanian Bogor, Kampus IPB \\ Darmaga, Bogor 16680
}

\begin{abstract}
Rice farming in Soreang district of Bandung Regency face problems that pose a threat to the sustainability of food security. This research objectives is to analyse and assess the sustainability of rice farming in Soreang District with Rapid Appraisal Usahatani Padi (RAP-FARM) using Multidimensional Scaling (MDS) method. Results shows rice farming in Soreang District assessment using RAP-FARM yield 49.07 in sustainability index which can be categorized as less sustainable. Leverage analysis results showed that out of 48 existing attributes, 21 sensitive attributes proven to have influence on the rice farming sustainability index. The perspective analysis shows that there are 6 key factors that have significant influence on wetland rice farming which are: (1) conformity of land usage to the land properties, (2) farmers motivation, (3) organic material usage and utilization of farm waste, (4) freedom from pest infestations and diseases, (5) land fertility, and (6) usage of chemical pesticides. The efforts for improving rice farming in Soreang Regency require a sustainability index value by way of managing and repairing sensitive attributes with attribute 21 focus on improvements of the sensitive 6 key factors attribute against the rice farming.
\end{abstract}

Keywords: sustainability, rice farming, Soreang

(Diterima: 11-10-2016; Disetujui: 22-03-2017)

\section{Pendahuluan}

Indonesia sebagai Negara yang berdaulat, berkomitmen untuk mewujudkan ketahanan pangan, hal ini tertuang dalam Undang-Undang Nomor 18 Tahun 2012 tentang Pangan, dan ditindaklanjuti dengan Peraturan Pemerintah Republik Indonesia Nomor 17 Tahun 2015 tentang ketahanan pangan dan gizi yang mengamanatkan bahwa pemerintah bersama masyarakat bertanggung jawab untuk mewujudkan ketahanan pangan bagi seluruh rakyat. Ketahanan pangan diartikan sebagai kondisi terpenuhinya pangan bagi rumah tangga yang tercermin dari tersedianya pangan yang cukup, baik jumlah maupun mutunya, aman, merata, dan terjangkau.

Padi adalah komoditas pangan strategis nasional dan memiliki sensitivitas yang tinggi ditinjau dari aspek politis, ekonomi, dan kerawanan sosial. Peran strategis padi dalam perekonomian nasional adalah: (1) merupakan bahan pangan pokok bagi $95 \%$ lebih penduduk Indonesia dengan pangsa konsumsi energi yang berasal dari beras lebih dari 55\%; (2) sekitar 30\% total pengeluaran rumah tangga miskin dialokasikan untuk beras; dan (3) usahatani padi menyediakan kesempatan kerja dan sumber pendapatan bagi lebih dari 25,6 juta rumah tangga petani (Suryana, 2005).

Produksi padi sawah di Kabupaten Bandung tahun 2004 - 2011 cenderung berfluktuatif, pada tahun 2004 produksi padi sebesar 425.914 ton, menurun menjadi 235.000 ton pada tahun 2005 , kemudian pada tahun
2006 meningkat menjadi 394.391 ton dan pada tahun 2011 meningkat menjadi 472.843 ton (Hadinata dan Sugiyanto, 2013). Kabupaten Bandung merupakan bagian dari wilayah pengembangan metropolitan Bandung yang merupakan hiterland serta daerah penyangga Kota Bandung dan salah satu Kabupaten yang mempunyai ketahanan pangan yang baik, namun perkembangan kegiatan Kota Bandung memaksa terjadi pergeseran kegiatan ekonomi ke Kabupaten Bandung.

Tantangan utama dalam penyediaan pangan dihadapkan pada ketersediaan sumberdaya lahan yang semakin langka (lack of resources), baik luas maupun kualitas serta konflik penggunaan (conflict of interest) (Pasandaran, 2006). Kelangkaan tersebut disebabkan semakin meningkatnya konversi lahan pertanian ke non pertanian yang bersifat permanen (irreversible). Alih fungsi lahan pertanian di Kabupaten Bandung selama 2004-2011 adalah sebesar 1.898,32 Ha atau 4,96\% dari seluruh sawah di Kabupaten Bandung. Alih fungsi lahan di Kecamatan Soreang sendiri sebesar 112,98 Ha atau $0,30 \%$ berdampak signifikan pada hilangnya produksi padi yaitu sebesar 1.669,36 ton/tahun (Hadinata dan Sugiyanto, 2013).

Usaha untuk meningkatkan produksi padi melalui peningkatan produktivitas juga terhambat oleh keterbatasan teknologi dan infrastuktur, telah dicapainya batas maksimum potensi hasil varietas, penurunan kualitas lahan karena terdegradasi dari penggunaan pupuk inorganik secara berlebihan, 
semakin terbatasnya sumber daya air, variabilitas iklim, dan meningkatnya serangan organisme pengganggu tanaman yang resisten terhadap penggunaan pestisida kimiawi (Sumarno, 2006).

Saat ini kontribusi Kabupaten Bandung terhadap produksi padi Jawa Barat kurang lebih mencapai 7\% setiap tahunnya, dan lebih kurang memasok 50-70 ton per hari ke pasar induk Cipinang Jakarta (Pemkab Bandung, 2014). Kabupaten Bandung menetapkan kebijakan pada salah satu kecamatan yaitu kecamatan Soreang. Permasalahan yang timbul dapat memperlemah ketahanan pangan nasional, mengingat Kecamatan Soreang termasuk wilayah pengembangan Soreang-Kutawaringin-Katapang sebagai salah satu lumbung beras andalan di bumi priangan.

Tujuan penelitian ini, menilai dan menganalisis status keberlanjutan usahatani padi sawah di Kecamatan Soreang Kabupaten Bandung berdasarkan 5 dimensi keberlanjutan (Suyitman et al., 2009), yaitu: dimensi ekologi, ekonomi, sosial-budaya, teknologi-infrastuktur, dan hukum-kelembagaan. Selain itu, penelitian ini juga bertujuan mengidentifikasi faktor kunci penentu keberlanjutan untuk pengembangan usahatani padi sawah di Kecamatan Soreang Kabupaten Bandung pada masa depan.

\section{Metode Penelitian}

\subsection{Tempat dan Waktu Penelitian}

Lokasi penelitian adalah di Kecamatan Soreang Kabupaten Bandung Provinsi Jawa Barat. Penetapan lokasi penelitian dipilih secara sengaja (purposive) sebanyak 10 (sepuluh) desa yaitu Desa Sadu, Desa Sukajadi, Desa Sukanagara, Desa Panyirapan, Desa Karamatmulya, Desa Soreang, Desa Pamekaran, Desa Parungserab, Desa Sekarwangi, dan Desa Cingcin. Penelitian dilaksanakan pada bulan Januari sampai dengan Mei 2016.

\subsection{Jenis dan Sumber Data}

Jenis data dalam penelitian ini dikelompokan menjadi dua yaitu data primer dan data sekunder. Data primer diperoleh melalui pengamatan langsung di lapangan (observasi) dan hasil wawancara mendalam (in depth interview) dengan 129 petani dan 20 stakeholders. Informan dipilih menggunakan purposive sampling dan identifikasi stakeholders dilakukan dengan metode snowball sampling yaitu stakeholders merekomendasikan stakeholders lainnya sebagai responden (Wildemuth 2009). Data sekunder diperoleh dari dokumen yang dipublikasikan oleh Pemerintah Kecamatan Soreang, Dinas Pertanian Kota Soreang dan Badan Pusat Statistik (BPS) Kabupaten Bandung baik berupa profil desa, monografi, buku sensus pertanian, laporan hasil penelitian, dan dokumen lainnya mengenai peraturan perundang-undangan, tupoksi, dan rencana strategis pengelolaan yang dimiliki oleh setiap instansi yang terkait.

\subsection{Metode Analisis}

Status keberlanjutan usahatani padi sawah dinyatakan dalam bentuk indeks keberlanjutan berdasarkan pendekatan Rap-Farm dengan menerapkan teknik MDS (Multidimensional Scaling) (Fisheries, 2002). Pendekatan Rap-Farm dimodifikasi dari program Rapfish (Rapid Assessment Techniques for Fisheries) yang dikembangkan oleh Fisheries Center, University of British Columbia (Fauzi dan Anna, 2005). Metode MDS merupakan teknik analisis statistik yang mentransformasi setiap dimensi dan multidimensi pada dimensi keberlanjutan usahatani padi sawah (Rao and Rogers, 2006).

Menurut Nurmalina (2008), teknik MDS memetakan dua titik atau objek yang sama dalam satu titik yang saling berdekatan. Sebaliknya, obyek atau titik yang berbeda digambarkan dengan titik-titik yang berjauhan. Nilai skor pada setiap atribut akan membentuk suatu matriks $X(n \times p)$, dimana $n$ adalah jumlah wilayah beserta titik-titik acuannya dan $\mathrm{p}$ adalah jumlah atribut yang digunakan. Nilai skor tersebut kemudian di standardisasi untuk setiap nilai skor atribut, sehingga setiap atribut memiliki bobot seragam dan perbedaan antarskala pengukuran dapat dihilangkan. Metode standardisasi tersebut, sebagai berikut :

keterangan:

$$
X_{i k} s d=\frac{X_{i k}-X_{k}}{S_{k}}
$$

$$
\begin{aligned}
X_{i k} s d= & \text { Nilai skor standar wilayah (termasuk titik } \\
& \text { acuannya) ke } \mathrm{i}=1,2, \ldots \mathrm{n}, \text { pada setiap } \\
& \text { atribut ke } \mathrm{k}=1,2, \ldots \mathrm{p} ; \\
X_{i k}= & \text { Nilai skor awal wilayah (termasuk titik- } \\
& \text { titik acuannya) ke } \mathrm{i}=1,2, \ldots \mathrm{n}, \text { pada setiap } \\
& \text { atribut ke } \mathrm{k}=1,2, \ldots \mathrm{p} ; \\
X_{k}= & \text { Nilai tengah skor pada setiap atribut ke } \mathrm{k}= \\
& 1,2, \ldots \mathrm{p} ; \\
S_{k}= & \text { Simpangan baku skor pada setiap atribut ke } \\
& \mathrm{k}=1,2, \ldots \mathrm{p} .
\end{aligned}
$$

Menurut Fauzi (2002), teknik MDS dalam Rapfish dilakukan dengan menghitung jarak terdekat dari Euclidian distance berdasarkan persamaan (1) berikut:

$d_{12}=\sqrt{\left(x_{1}-x_{2}\right)^{2}+\left(y_{1}-y_{2}\right)^{2}+\cdots}$

Jarak Euclidean antara dua titik tersebut $\left(\mathrm{d}_{12}\right)$ kemudian diproyeksikan ke dalam jarak Euclidean dua dimensi $\left(D_{12}\right)$ berdasarkan rumus regresi $(2)$ berikut:

$d_{12}=a+b D_{12}+e$; e adalah error

Pada Rapfish, proses regresi tersebut menggunakan algoritma ALSCAL dengan prinsip membuat pengulangan (iteration) proses regresi tersebut sehingga mampu menghasilkan nilai error terkecil. Menurut Kavanagh and Pitcher (2004) algoritma ALSCAL pada Rapfish memaksa agar nilai intercept pada persamaan tersebut sama dengan nol $(\mathrm{a}=0)$ sehingga persamaan (2) menjadi persamaan (3) berikut: 
$d_{12}=b D_{12}+e$.

Proses pengulangan terhenti, jika nilai stress lebih kecil dari 0.25. Nilai Stress diperoleh berdasarkan persamaan (4).

Stress $=\sqrt{\frac{1}{m} \sum_{k=1}^{m}\left[\frac{\sum_{i} \sum_{j}\left(D_{i j k}-d_{i j k}\right)^{2}}{\sum_{i} \sum_{j} d_{i j k}^{2}}\right]}$

Pengaruh error akan muncul dalam analisis MDS yang disebabkan oleh berbagai hal, seperti: 1) kesalahan dalam pembuatan skor karena kesalahan pemahaman terhadap atribut atau kondisi lokasi penelitian yang belum sempurna, 2) variasi nilai akibat perbedaan opini atau penilaian oleh peneliti, 3) proses analisis MDS yang berulang-ulang, kesalahan pemasukan data atau ada data yang hilang, dan tingginya nilai stress. Nilai stress $<25 \%$ merupakan nilai stress yang dapat diterima. Evaluasi pengaruh error pada proses pendugaan nilai ordinasi keberlanjutan dapat dilakukan dengan menggunakan analisis "Montecarlo".

Metode penentuan indeks keberlanjutan usahatani padi sawah dengan teknik Rapfish dilakukan berdasarkan sistematika yang telah ditentukan. Menurut Nababan et al. (2008) penentuan Indeks dan status keberlanjutan berdasarkan tahapan: 1) pengkajian atribut-atribut pada setiap dimensi keberlanjutan dan menilai atribut tersebut berdasarkan data aktual melalui pengamatan lapangan, wawancara bersama pakar, dan kajian pustaka, 2) nilai skor atributatribut setiap dimensi keberlanjutan kemudian dianalisis pada program Microsoft Excell dengan menggunakan template yang telah disiapkan sebelumnya, sehingga diperoleh suatu besaran nilai yang dikenal dengan indeks keberlanjutan, 3) mengkategorikan nilai indeks keberlanjutan berdasarkan selang keberlanjutan untuk memperoleh status keberlanjutan. Selang nilai skor keberlanjutan setiap dimensi, antara lain: buruk (0,00-25,00), kurang (25,01-50,00), cukup $(50,01-75,00)$, dan baik $(75,01-$ $100,00)$. Hasil lain yang diperoleh dalam analisis MDS adalah penentuan faktor pengungkit (leverage factors) yang merupakan faktor-faktor strategis pengelolaan usahatani padi sawah di masa depan (Pitcher and Preikshot, 2001). Faktor pengungkit tersebut, berguna dalam penentuan faktor penting pengelolaan lingkungan yang lebih baik.

Penentuan faktor kunci keberlanjutan dilakukan dengan menggunakan analisis prospektif (Participatory Prospective Analysis). Analisis tersebut digunakan untuk menentukan faktor penting yang berpengaruh terhadap usahatani padi sawah. Analisis prospektif melibatkan responden pakar untuk berpartisipasi dalam rangka mengetahui, menyelidiki, dan mengantisipasi perubahan terhadap sistem yang mampu memberikan hasil cepat (Bourgeois and Jesus, 2004). Penilaian faktor penting dilakukan dengan mempertimbangkan dampak langsung faktor pengungkit terhadap faktor pengungkit lainnya. Menurut Godet (1999) pengaruh antar faktor diberikan skor oleh responden pakar, antara lain: (a) skor 0 apabila tidak ada pengaruh, (b) skor 1 apabila berpengaruh kecil, (c) skor 2 apabila berpengaruh sedang, dan (d) skor 3 apabila berpengaruh sangat kuat.

Menurut Burgeois and Jesus (2004) hasil analisis berbagai faktor atau variabel seperti pada Gambar 2 menunjukkan bahwa faktor-faktor atau variabelvariabel yang berada pada: (1) kuadran I (input) memuat faktor penting atau penggerak (driving variabels) yang paling kuat dalam sistem karena memiliki pengaruh kuat dengan ketergantungan rendah, (2) kuadran II (stakes) memuat faktor peubah kuat karena mempunyai pengaruh dan ketergantungan yang kuat (leverage variables), (3) kuadran III (output) memuat faktor-faktor berpengaruh kecil dengan ketergantungan tinggi, dan (4) kuadran IV (unused) memuat faktorfaktor yang mempunyai pengaruh dan ketergantungan kecil.

\section{Hasil dan Pembahasan}

\subsection{Status Keberlanjutan Usahatani Padi Sawah di Kecamatan Soreang}

Hasil analisis Rap-Farm (Gambar 1) menunjukkan bahwa usahatani padi sawah di Kecamatan Soreang Bandung memiliki nilai indeks keberlanjutan sebesar 49,07, sehingga status kerberlanjutan berkategorikan kurang berkelanjutan. Nilai indeks keberlanjutan tersebut dihasilkan berdasarkan penilaian terhadap atribut yang tercakup dalam 5 dimensi keberlanjutan, antara lain: dimensi ekologi (11 atribut), dimensi ekonomi (10 atribut), dimensi sosial-budaya (10 atribut), dimensi teknologi-infrastuktur (8 atribut), dan dimensi hukumkelembagaan (9 atribut).

Stress analisis MDS masing-masing dimensi dan rataannya memiliki nilai $<0,25$ dimana semakin kecil nilai stress maka output analisis MDS semakin baik. Koefisien determinasi $\left(\mathrm{R}^{2}\right)$ pada setiap dimensi dan rataannya memiliki nilai yang tinggi. Hal ini ditunjukkan dengan besaran nilai yang mendekati 1. Berdasarkan kedua parameter statistik tersebut (Tabel 1), disimpulkan bahwa seluruh atribut yang digunakan pada setiap dimensi mampu menggambarkan keberlanjutan usahatani padi sawah. 


\begin{tabular}{|c|c|c|c|}
\hline \multirow{7}{*}{$\begin{array}{l}\text { Kelembagaan } \\
\text { anjutan }\end{array}$} & Dimensi & Indeks & Status \\
\hline & Ekologi & 49,02 & Kurang \\
\hline & Ekonomi & 55,16 & Cukup \\
\hline & Sosial-Budaya & 45,87 & Kurang \\
\hline & $\begin{array}{l}\text { Teknologi- } \\
\text { Infrastruktur }\end{array}$ & 44,57 & Kurang \\
\hline & $\begin{array}{c}\text { Hukum- } \\
\text { Kelembagaan }\end{array}$ & 50,73 & Cukup \\
\hline & Multidimensi & 49,07 & Kurang \\
\hline
\end{tabular}

Gambar 1. Indeks dan status keberlanjutan usahatani padi sawah di Kecamatan Soreang Kabupaten Bandung

Tabel 1. Parameter statistik (goodness of fit) analisis indeks keberlanjutan usahatani padi sawah

\begin{tabular}{cccccc}
\hline \multicolumn{7}{c}{$\begin{array}{c}\text { Tabel 1. Parameter statistik (goodness of fit) analisis indeks keberlanjutan usahatani padi sawah } \\
\text { Parameter } \\
\text { statistik }\end{array}$} & Ekologi & Ekonomi & $\begin{array}{c}\text { Sosial- } \\
\text { Budaya }\end{array}$ & $\begin{array}{c}\text { Teknologi- } \\
\text { Infrastruktur }\end{array}$ & $\begin{array}{c}\text { Hukum- } \\
\text { Kelembagaan }\end{array}$ & \begin{tabular}{c} 
Rataan \\
\cline { 2 - 6 }
\end{tabular} \\
\cline { 2 - 6 } & 0,18 & 0,18 & 0,17 & 0,18 & 0,15 \\
$\mathrm{R}^{2}$ & 0,90 & 0,88 & 0,88 & 0,90 & 0,17 \\
\hline
\end{tabular}

Tabel 2. Hasil analisis Monte Carlo nilai Rap-Farm pada selang kepercayaan 95 persen

\begin{tabular}{lccr}
\hline \multicolumn{1}{c}{ Dimensi } & MDS & Monte Carlo & Selisih \\
\hline Ekologi & 49,02 & 49,01 & 0,01 \\
Ekonomi & 55,16 & 54,56 & 0,60 \\
Sosial-Budaya & 45,87 & 45,47 & 0,39 \\
Teknologi-Infrastruktur & 45,57 & 44,62 & 0,95 \\
Hukum-Kelembagaan & 50,73 & 49,73 & 1,00 \\
Multidimensi & 49,07 & 48,68 & 0,39 \\
\hline
\end{tabular}

\begin{tabular}{|c|c|c|c|c|c|c|}
\hline Desa & Ekologi & Ekonomi & $\begin{array}{l}\text { Sosial- } \\
\text { Budaya }\end{array}$ & $\begin{array}{c}\text { Teknologi- } \\
\text { Infrastruktur }\end{array}$ & $\begin{array}{c}\text { Hukum- } \\
\text { Kelembagaan }\end{array}$ & Multidimensi \\
\hline Sukanagara & 37,56 & 39,50 & 35,61 & 30,48 & 34,81 & 35,59 \\
\hline Sadu & 50,81 & 41,60 & 45,00 & 50,78 & 40,48 & 45,73 \\
\hline Sukajadi & 35,48 & 29,80 & 65,05 & 42,03 & 41,96 & 42,86 \\
\hline Panyirapan & 51,69 & 40,66 & 40,55 & 29,03 & 40,48 & 40,48 \\
\hline Karmatmulya & 46,37 & 55,25 & 36,42 & 68,01 & 65,33 & 54,28 \\
\hline Soreang & 42,77 & 53,54 & 46,14 & 50,93 & 79,13 & 54,50 \\
\hline Pamekaran & 46,62 & 44,88 & 38,81 & 45,81 & 53,54 & 45,93 \\
\hline Parungserab & 41,16 & 49,26 & 46,49 & 30,35 & 63,73 & 46,20 \\
\hline Sekarwangi & 39,19 & 53,30 & 45,02 & 29,17 & 44,22 & 42,18 \\
\hline Cingcin & 45,71 & 38,73 & 30,61 & 51,95 & 51,41 & 43,68 \\
\hline
\end{tabular}

Hasil analisis Monte Carlo (Tabel 2) menunjukkan perbedaan nilai yang kecil antara nilai indeks keberlanjutan MDS dan Monte Carlo pada selang kepercayaan 95 persen. Perbedaan nilai yang kecil tersebut, menunjukkan: (1) kesalahan pembuatan skor setiap atribut relatif kecil, (2) variasi pemberian skor akibat perbedaan opini relatif kecil, (3) proses analisis MDS yang berulang relatif stabil, dan (4) kesalahan pemasukan data dan data yang hilang dapat dihindari. Perbedaan ini juga menunjukkan bahwa analisis yang dikaji memiliki tingkat kepercayaan yang tinggi. Beberapa parameter hasil uji statistik ini menunjukkan bahwa metode Rap-Farm cukup baik untuk dipergunakan sebagai salah satu alat evaluasi keberlanjutan usahatani padi sawah secara kuantitatif dan cepat (rapid appraisal).

\subsection{Status Keberlanjutan Usahatani Padi Sawah di Perdesaan Kecamatan Soreang}

Berdasarkan Tabel 3 hasil analisis Rap-Farm multidimensi menunjukkan nilai indeks keberlanjutan usahatani padi sawah di Kecamatan Soreang bervariasi. Sebagian besar desa di Kecamatan Soreang memperoleh nilai ikb-rice berkisar 42,18 - 46,20 termasuk kategori kurang berkelanjutan diantaranya yaitu Desa Sadu, Desa Sukajadi, Desa Panyirapan, Desa Pamekaran, Desa Parungserab, Desa Sekarwangi, dan Desa Cingcin. Terdapat dua desa yang memperoleh nilai indeks keberlanjutan diatas 50,01 yaitu Desa Karamatmulya dan Desa Soreang digolongkan kedalam kategori cukup berkelanjutan. Desa Sukanagara memperoleh nilai indeks terendah dibandingkan sembilan desa lainnya di Kecamatan Soreang dengan perolehan nilai indeks keberlanjutan sebesar 35,59 termasuk kategori kurang berkelanjutan.

Desa Karamatmulya dan Desa Soreang secara multidimensi termasuk kategori cukup berkelanjutan, namun hasil analisis Rap-Farm menunjukkan pada dimensi ekologi dan dimensi sosial-budaya masih termasuk kurang berkelanjutan, hal ini ditunjukkan 
dengan nilai indeks dibawah 50,00. Nilai indeks keberlanjutan untuk dimensi ekologi tertinggi diperoleh Desa Panyirapan sebesar 51,69 tergolong cukup berkelanjutan namun secara multidimensi Desa Panyirapan masih termasuk kategori kurang berkelanjutan. Hal ini serupa pada Desa Sukajadi yang memperoleh nilai indeks keberlanjutan tertinggi untuk dimensi sosial-budaya sebesar 65,05 tergolong cukup berkelanjutan, namun secara multidimensi Desa Sukajadi masih termasuk kategori kurang berkelanjutan

Keadaan tersebut menunjukkan bahwa, meskipun nilai indeks keberlanjutan multidimensi tergolong kategori cukup berkelanjutan belum tentu secara keseluruhan kelima dimensi yang diamati memiliki nilai ikb-rice tergolong cukup berkelanjutan. Hal ini dikarenakan untuk memperoleh status keberlanjutan cukup berkelanjutan secara multidimensi, diperlukan lima dimensi yang mempengaruhi nilai indeks keberlanjutan multidimensi suatu desa atau kecamatan. Oleh karena itu diperlukan pengembangan dan peningkatan tidak hanya pada dimensi tertentu tetapi secara keseluruhan/holistik pada tiap dimensi agar nilai indeks keberlanjutan multidimensi menjadi lebih baik.

\subsection{Atribut Sensitif}

Hasil analisis leverage dimensi ekologi (Gambar 2), menunjukkan dari 11 atribut yang dianalisis terdapat 5 atribut sensitif berpengaruh terhadap usahatani padi sawah. Penentuan 5 atribut sensitif tersebut, ditentukan dengan cara memilah atribut yang memiliki nilai perubahan root mean square (RMS) lebih dari setengah skala nilai pada sumbu x. Kelima atribut sensitif terhadap keberlanjutan tersebut, antara lain: (1) pemakaian pestisida kimia, (2) lahan (kesuburan tanah), (3) penggunaan bahan organik dan pemanfaatan limbah pertanian, (4) kesesuaian lahan dengan tata guna lahan, dan (5) bebas serangan hama dan penyakit. Empat dari lima atribut sensitif tersebut memiliki keterkaitan erat terhadap keberlanjutan ekologi, yaitu atribut pemakaian pestisida kimia, lahan (kesuburan tanah), penggunaan bahan organik dan pemanfaatan limbah pertanian, dan bebas serangan hama dan penyakit.

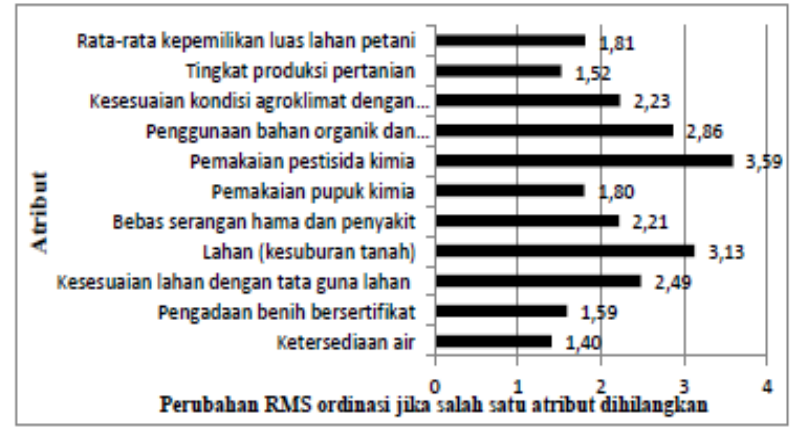

Gambar 2. Atribut sensitif yang mempengaruhi keberlanjutan dimensi ekologi usahatani padi sawah di Kecamatan Soreang Kabupaten Bandung

Hasil analisis leverage dimensi ekonomi (Gambar 3), menunjukkan dari 10 atribut yang dianalisis terdapat
4 atribut sensitif berpengaruh terhadap usahatani padi sawah. Keempat atribut sensitif terhadap keberlanjutan tersebut, antara lain: (1) transfer keuntungan dari usahatani padi, (2) rataan penghasilan petani relatif terhadap UMR Kabupaten Bandung, (3) Fluktuasi harga, dan (4) Harga Gabah Kering Giling (GKG) tingkat petani. Tiga dari empat atribut sensitif tersebut memiliki keterkaitan erat terhadap keberlanjutan ekonomi, yaitu rataan penghasilan petani relatif terhadap UMR, fluktuasi harga, dan Harga Gabah Kering Giling (GKG) tingkat petani.

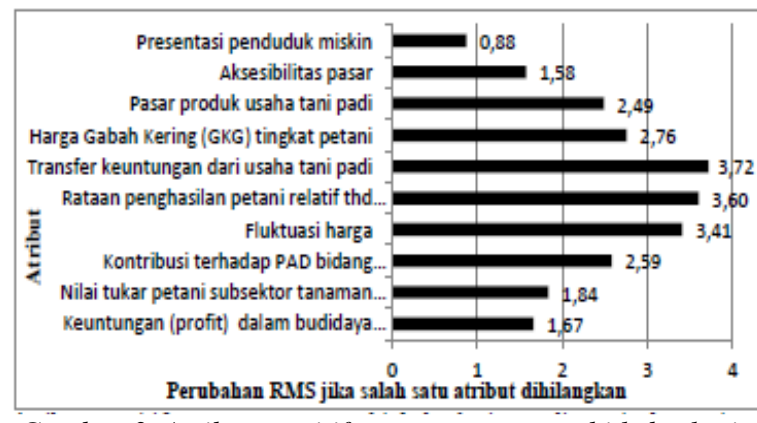

Gambar 3. Atribut sensitif yang mempengaruhi keberlanjutan dimensi ekonomi usahatani padi sawah di Kecamatan Soreang Kabupaten Bandung

Hasil analisis leverage dimensi sosial-budaya (Gambar 4), menunjukkan dari 10 atribut yang dianalisis terdapat 5 atribut sensitif berpengaruh terhadap usahatani padi sawah. Kelima atribut sensitif terhadap keberlanjutan tersebut, antara lain: (1) motivasi petani bertani, (2) pengetahuan dan dukungan terhadap lingkungan pertanian, (3) frekuensi konflik pertanian, (4) tingkat penyerapan tenaga kerja, dan (5) pertumbuhan rumah tangga petani. Tiga dari lima atribut sensitif tersebut memiliki keterkaitan erat terhadap keberlanjutan sosial-budaya, yaitu motivasi petani bertani, tingkat penyerapan tenaga kerja, pertumbuhan rumah tangga petani.

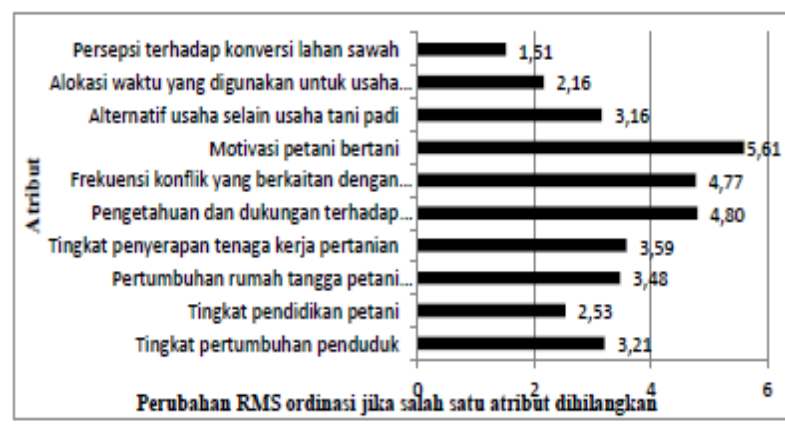

Gambar 4. Atribut sensitif yang mempengaruhi keberlanjutan dimensi sosial-budaya usahatani padi sawah di Kecamatan Soreang kabupaten Bandung

Hasil analisis leverage dimensi teknologi-infrastruktur (Gambar 5), menunjukkan dari 8 atribut yang dianalisis terdapat 4 atribut sensitif berpengaruh terhadap usahatani padi sawah. Kelima atribut sensitif terhadap keberlanjutan tersebut, antara lain: (1) kondisi jalan usahatani desa, (2) akses terhadap perkembangan iptek, (3) ketersediaan sarana prasarana usahatani, (4) 
saluran irigasi. Tiga dari empat atribut sensitif tersebut memiliki keterkaitan erat terhadap keberlanjutan teknologi-infrastruktur, yaitu kondisi jalan usahatani desa, ketersediaan sarana prasarana usahatani, dan saluran irigasi.

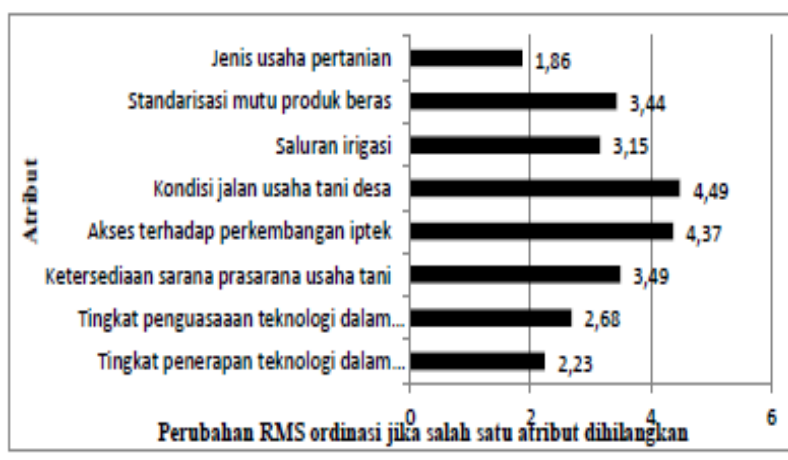

Gambar 5. Atribut sensitif yang mempengaruhi keberlanjutan dimensi teknologi-infrastruktur usahatani padi sawah di Kecamatan Soreang Kabupaten Bandung

Hasil analisis leverage dimensi hukum-kelembagaan (Gambar 6), menunjukkan dari 9 atribut yang dianalisis terdapat 3 atribut sensitif berpengaruh terhadap usahatani padi sawah. Kelima atribut sensitif terhadap keberlanjutan tersebut, antara lain: (1) penyuluhan pertanian, (2) jumlah penyaluran kredit, (3) keberadaan kelompok tani. Dua dari tiga atribut sensitif tersebut memiliki keterkaitan erat terhadap keberlanjutan hukum-kelembagaan, yaitu penyuluhan pertanian dan keberadaan kelompok tani.

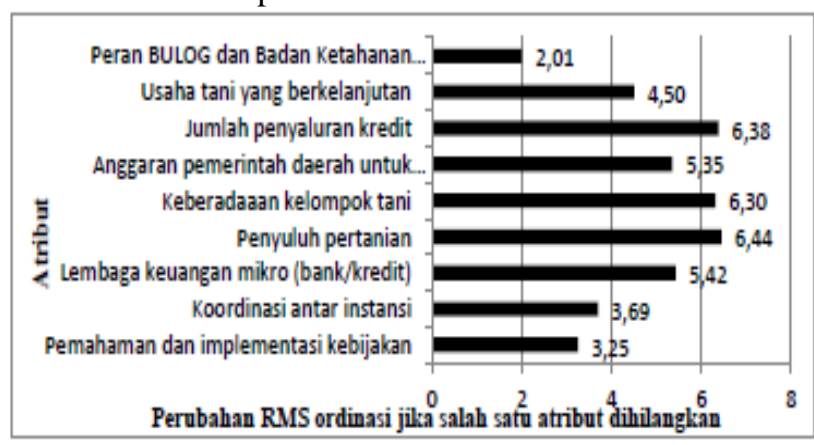

Gambar 6. Atribut sensitif yang mempengaruhi keberlanjutan dimensi hukum-kelembagaan usahatani padi sawah di Kecamatan Soreang Kabupaten Bandung

Berdasarkan hasil analisis leverage pada masingmasing dimensi keberlanjutan, dari 48 atribut diperoleh 21 atribut sensitif dari 5 dimensi keberlanjutan, yaitu:

a. Dimensi ekologi: (1) pemakaian pestisida kimia, (2) lahan (kesuburan tanah), (3) penggunaan bahan organik dan pemanfaatan limbah pertanian, (4) kesesuaian lahan dengan tata guna lahan, dan (5) bebas serangan hama dan penyakit.

b. Dimensi ekonomi: (1) transfer keuntungan dari usahatani padi, (2) rataan penghasilan petani relatif terhadap UMR Kabupaten Bandung, (3) fluktuasi harga, dan (4) Harga Gabah Kering Giling (GKG) tingkat petani.

c. Dimensi sosial-budaya: (1) motivasi petani bertani, (2) pengetahuan dan dukungan terhadap lingkungan pertanian, (3) frekuensi konflik pertanian, (4) tingkat penyerapan tenaga kerja, dan (5) pertumbuhan rumah tangga petani.

d. Dimensi teknologi-infrastruktur: (1) kondisi jalan usahatani desa, (2) akses terhadap perkembangan iptek, (3) ketersediaan sarana prasarana usahatani, dan (4) saluran irigasi.

e. Dimensi hukum-kelembagaan: (1) penyuluhan pertanian, (2) jumlah penyaluran kredit, dan (3) keberadaan kelompok tani.

\subsection{Faktor Kunci Analisis Prospektif}

Konsep pembangunan berkelanjutan bertujuan menciptakan keseimbangan antara pertumbuhan ekonomi (dimensi ekonomi), pelestarian lingkungan (dirnensi ekologi), pemerataan (dimensi sosial-budaya). Beberapa pendapat menambahkan dimensi teknologi-infrastruktur (pengembangan dan penerapan teknologi pada infrastruktur yang lebih baik), hukum-kelembagaan (pematuhan hukum dan berfungsinya kelembagaan) bagi pelaksanaan pembangunan berkelanjutan. Penerapan konsep pembangunan berkelanjutan pada sistem nyata memerlukan komitmen kuat pelaku utama sistem (stakeholders) untuk menjamin keberhasilan pembangunan.

Analisis prospektif mampu mengeksplorasi kemungkinan masa depan berdasarkan tujuan yang telah ditentukan. Tahap penentuan indeks dan status keberlanjutan bertujuan memberikan gambaran keadaaan usahatani padi sawah aktual (existing condition). Analisis prospektif bertujuan mempersiapkan tindakan strategis di masa depan dengan cara menentukan faktor kunci yang berperan penting terhadap berbagai kemungkinan yang akan terjadi di masa depan.

Berdasarkan penilaian 21 atribut sensitif tersebut, teridentifikasi 6 faktor kunci/dominan yang memiliki berpengaruh kuat. Tiga faktor kunci diantaranya merupakan faktor kunci yang mempunyai pengaruh kuat antar faktor walaupun dengan ketrgantungan yang kurang kuat, yaitu (1) kesesuaian lahan dengan tata guna lahan, (2) motivasi petani bertani, dan (3) penggunaan bahan organik dan pemanfaatan limbah pertanian. Sementara itu, tiga atribut lainnya merupakan faktor yang mempunyai pengaruh dan ketergantungan yang kuat yaitu: (1) bebas serangan hama dan penyakit, (2) lahan (kesuburan tanah), dan (3) pemakaian pestisida kimia. Dengan demikian, keenam faktor tersebut perlu dikelola dengan baik di masa yang akan datang agar keberlanjutan usahatani padi sawah dapat dipertahankan bahkan ditingkatkan.

\section{Kesimpulan}

Berdasarkan kondisi eksisting, hasil analisis usahatani padi sawah di Kecamatan Soreang Kabupaten Bandung, secara multidimensi menunjukkan kategori kurang berkelanjutan. Terdapat dua desa di Kecamatan Soreang yang tergolong cukup berkelanjutan yaitu Desa Karamatmulya dan Desa 
Soreang. Secara agregat, atribut yang sensitif mempengaruhi keberlanjutan usahatani padi sawah dikelompokkan menjadi 2 faktor, yaitu: 1) subsistem hulu (on farm) dan 2) sumberdaya manusia petani. Rendahnya motivasi petani untuk bertani dan rendahnya kesadaran petani akan penggunaan input pertanian yang berasal dari lingkungan menyebabkan usahatani padi sawah kurang berkelanjutan. Untuk itu perlu dilakukan peningkatan kualitas sumberdaya manusia, yaitu kesadaran tentang pentingnya usahatani padi sawah terpadu, baik bagi instansi pemerintah khususnya Dinas Pertanian, petani dan masyarakat, dukungan sarana prasarana input pertanian berbasiskan pertanian organik, serta penyuluhan pertanian untuk meningkatkan keberlanjutan usahatani padi sawah di Kecamatan Soreang Kabupaten Bandung.

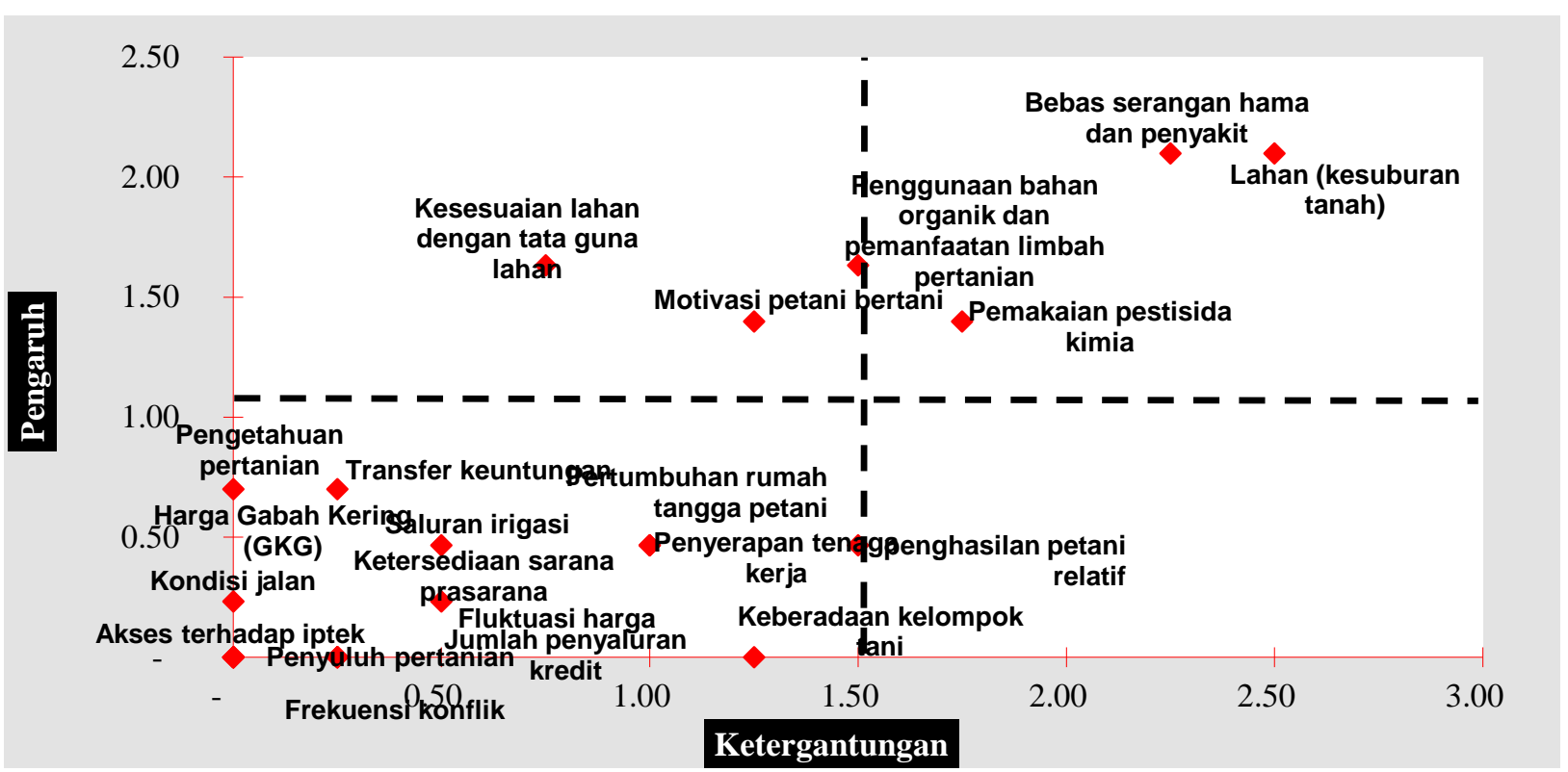

Gambar 7. Faktor kunci/dominan yang berpengaruh pada usahatani padi sawah di kecamatan Soreang Kabupaten Bandung

\section{Daftar Pustaka}

[1] Bourgeois, R. and F. Jesus, 2004. Participatory Prospective Analysis, Exploring and Anticipating Challenges with Stakeholders. Center for Alleviation of Poverty through Secondery Crops Development in Asia and The Pacific and French Agricultural Reasearch Center for Internasional Development. Monograph (46) : $1-29$.

[2] Fauzi, A. dan S. Anna, 2005. Pemodelan Sumber Daya Perikanan dan Lautan untuk Analisis Kebijakan. Gramedia Pustaka Utama. Jakarta.

[3] Fauzi, A., 2002. Penilaian depresiasi sumberdaya perikanan sebagai bahan pertimbangan penentuan kebijakan pembangunan perikanan. Jumal Pesisir dan Lautan Vol. 4 (2). pp: 36-49.

[4] Fisheries Centre, 2002. Attributes of Rapfish Analysis for Ecological, Technological, Economic, Social and Ethical Evaluation Fields. Institute of Social and Economic Research Press. St John's Canada.

[5] Godet, M., 1999. Scenarios and Strategies, A Toolbox for Scenario Planning. Librairie des Arts et Meiters. Paris.

[6] Hadinata C dan Sugiyanto, 2013. Kebijakan Perlindungan Lahan Pertanian dan Alih Fungsi lahan Pertanian di Kabupaten Bandung. Jurnal Perencanaan Wilayah dan Kota Sekolah Arsitektur Perencanaan dan Pengembangan Kebijakan ITB 2 (2): $309-323$

[7] Kavanagh, P. and T. J. Pitcher, 2004. Implementing Microsoft Excel Software for Rapfish : A Technique for The Rapid Appraisal of Fisheries Status. University of British Columbia. Fisheries Centre Research Reports 12(2).

[8] Nababan, O. B, Y. D. Sari, dan M. Hermawan, 2008. Tinjauan Aspek Ekonomi Keberlanjutan Perikanan Tangkap Skala Kecil di Kabupaten Tegal Jawa Tengah. Buletin Ekonomi Perikanan 8(2).

[9] Nurmalina, R., 2008. Analisis Indeks dan Status Keberlanjutan Sistem Ketersediaan Beras di Beberapa Wilayah Indonesia. Jurnal Agro Ekonomi 26(1) : 47-79.
[10] Pasandaran E., 2006. Alternatif Kebijakan Pengendalian Konversi Lahan Sawah Beririgasi di Indonesia. Jurnal Litbang Pertanian 25(4): 123 - 129

[11] Pitcher, T. J. and D. Preikshot. 2001. Rapfish: A Rapid Appraisal Technique to Evaluate The Sustainability Status of Fisheries. Fisheries Research 49 (2001) : 255-270.

[12] Rao N. and Rogers P., 2006. Assessment of Agricultural Sustainability. Current Science. 91(41): $439-448$

[13] Sumarno, 2006. Sistem Produksi Padi Berkelanjutan dengan Penerapan Revolusi Hijau Lestari. Buku I. Pros. Seminar Nasional Sumberdaya Lahan Pertanian. Bogor, 14-15 September 2006.

[14] Suryana A., 2005. Pembangunan Pertanian Berkelanjutan Andalan Pembangunan Nasional. Makalah pada Seminar Sistem Pertanian Berkelanjutan untuk Mendukung Pembangunan Nasiosinal 15 Februari 2005. Universitas Sebelas Maret Solo.

[15] Suyitman, S. H. Sucahyo, C. Herison, dan Muladno, 2009. Status Keberlanjutan Wilayah Berbasis Peternakan di Kabupaten Situbondo untuk Pengembangan Kawasan Agropolitan. Jurnal Agro Ekonomi 27(2) : 165-191.

[16] Undang-Undang Nomor 41 Tahun 2009 tentang Perlindungan Lahan Pertanian Berkelanjutan. Jakarta.

[17] Undang-Undang Nomor 18 Tahun 2012 tentang Pangan. Jakarta.

[18] Wildemuth B. M., 2009. Application of Social Research Methods to Question in Informan and Library Science. Grennwood Publishing Group, London. 